\title{
Self-Reported Productivity Losses of People with Rheumatoid Arthritis in Alberta, Canada
}

\author{
Nguyen Xuan Thanh ${ }^{*}, 1,2$, Arto Ohinmaa ${ }^{1,2}$, Cheryl Barnabe ${ }^{3,4}$, Joanne Homik ${ }^{5}$, Susan G. Barr ${ }^{3,4}$, \\ Liam Martin ${ }^{3}$ and Walter P. Maksymowych ${ }^{5}$ \\ ${ }^{I}$ Institute of Health Economics, Edmonton, Alberta, Canada \\ ${ }^{2}$ Department of Public Health Sciences, University of Alberta, Edmonton, Alberta, Canada \\ ${ }^{3}$ Department of Medicine, University of Calgary, Calgary, Alberta, Canada \\ ${ }^{4}$ Department of Community Health Sciences, University of Calgary, Calgary, Alberta, Canada \\ ${ }^{5}$ Department of Medicine, University of Alberta, Edmonton, Alberta, Canada
}

\begin{abstract}
Objectives: To estimate the annual cost of productivity losses per person with RA by 0.5 increment in HAQscore, and the annual cost of productivity losses for Alberta province.

Methods: Using data from the Alberta Biologics Registry - a prospective observational cohort of consecutive patients receiving DMARD or anti-TNF therapies created in 2004, we compared the mean and median costs of productivity losses per patient per year between HAQ-score categories using multiple linear and quantile regressions, respectively. We used a prevalence-based approach to estimate the cost (in 2010 CA\$) of productivity losses of RA for Alberta.

Results: In total there were 1222 patients with RA interviewed at the baseline. Of this, 358 were the "current employees" and 204 were the "previous employees" totalling 563 patients for analyses. For all HAQ-score categories, the mean (median) of the cost per patient per year was estimated at \$18,242 $(\$ 3,840)$. The cost was increasing along with the HAQscore increase. The lowest cost $(\$ 6,295)$ was found in category HAQ $<=0.5$ and the highest $(\$ 31,095)$ in category HAQ>2.0. The significant differences were found between the worse categories (HAQ>1.5) and the better categories $(\mathrm{HAQ}<=1.5)$. The mean costs of productivity losses of RA for the province of Alberta were estimated at $\$ 270$ million. Conservatively, if median was used for mean, the costs for province would be $\$ 57$ million.

Conclusion: The results suggest that an improvement in the controlling of RA could have a significant economic impact in Alberta and that preventing HAQ-score from the worse categories may be associated with substantial savings in terms of productivity losses.
\end{abstract}

Keywords: Productivity loss, rheumatoid arthritis, HAQ score, Alberta, Canada.

\section{INTRODUCTION}

Rheumatoid arthritis (RA) is a chronic autoimmune arthritis characterized by a progressive joint damage which negatively affects patients' function and quality of life. It's estimated that patients with RA have a 7-time higher risk of disability as compared with age- and sex-matched controls [1]. Besides the consequences on the health status of individual, RA has a substantial economic impact on patients, their families, and society [2].

There are several studies of costs of RA and most of these studies estimate the costs of a typical case of RA or/and the costs of RA for a country [3]. It is estimated that direct and indirect costs (in 2011 Canadian dollars) per patient per year vary from $\$ 3,400$ to $\$ 21,800$ and from $\$ 2,300$ to 70,300 , respectively [4]. The total costs of RA was

*Address correspondence to this author at the Institute of Health Economics, 1200, 10405 Jasper Ave., NW, Edmonton, Alberta, T5J 3N4, Canada;

Tel: +1-780-4484881; Fax: +1-780-4480018; E-mail: tnguyen@ihe.ca estimated at $\$ 4.1$ billion in England for the year 1992 (of which indirect costs accounted for 52\%) [5], and at $\$ 17.1$ billion in the US for the year 1991 (of which indirect costs accounted for $70-74 \%$ ) [6]. This figure in Canada was $\$ 5.9$ billion for the year 2010 (of which the indirect costs accounted for 58\%) [7]. The methods used to estimate the cost of productivity losses varied across studies. Many indirect costs were overestimated, including lost days of unpaid work (students, homemakers, and retirees) [4].

However, there are neither studies estimating productivity losses per patient with RA by 0.5 increment in Health Assessment Questionnaires (HAQ)-scores, which is useful for economic evaluations of new drugs or technologies improving RA patients' function (measured by HAQ-scores) using a societal perspective, nor studies estimating productivity losses caused by RA for the province of Alberta.

The current study, therefore, aims to estimate the annual cost of productivity losses per person with RA by 0.5 
increment in HAQ-score, and the annual cost of productivity losses for the province of Alberta.

\section{MATERIALS AND METHODS}

The Alberta Biologics Registry is a prospective observational cohort of consecutive patients receiving Disease Modifying Anti-rheumatic Drugs (DMARD) or antiTumor Necrosis Factor (TNF) therapies created in the year 2004 [8]. We collect efficacy and safety data for all enrolled patients at baseline, 3 months, and every 6 months thereafter. This pharmacovigilance program is supported by Alberta Health and approved by the University of Calgary Health Research Ethics Board. All patients participating in the program provide informed consent for the collection and evaluation of clinical data in accordance with ethical standards described in the Declaration of Helsinki.

In this study, we analysed the data of the baseline survey where the patients were asked about the onset and duration of RA, socio-demographic characteristics, health related behaviours (e.g. smoking), co-morbidities, Health Assessment Questionnaires (HAQ), and illness-related employment history. We included patients who were "currently employed in paid work" and those who were "previously employed in paid work and stopped working permanently or retired earlier because of their RA". The "current employees" were asked "how many days over the last 6 months were you unable to work because of your RA?". Their answers for this question were multiplied by 2 to estimate the annual work-day loss for them. For the "previously employees" who stopped working permanently or retired earlier because of RA, the annual work-day loss was all work-days in the year or a half if stopped working or retired early before or after 64 years old, respectively. We estimated the number of all work-days in a year based on 8 hours a day, 5 days a week, and 49 weeks a year (we assumed 3 weeks for vacation per year). The number of working hour per day was the median of the "previous employees" who answered to the question: "how many hours per week, on average did you work?". We used a human capital method to estimate the cost of productivity losses caused by RA. The Albertan average wage per day in 2010 (\$196) was used as the monetary value for a work-day.

The included patients were exclusively categorized into 5 categories of HAQ-score collected at baseline: 1) HAQ-score from 0.0 to $0.5,2$ ) HAQ-score from 0.6 to $1.0,3) \mathrm{HAQ}$ score from 1.1 to $1.5,4) \mathrm{HAQ}$-score from 1.6 to 2.0 , and 5) HAQ-score from 2.1 to 3.0 (due to small number of patients having HAQ-core from 2.6 to 3.0, this category was not separated). Patients with missing value in HAQ-score were grouped as "unknown".

We estimated the mean and median costs of productivity losses per patient per year for each HAQ-score category. We used multiple linear and quantile regressions to compare the mean and median costs of productivity losses, respectively, between HAQ-core categories, accounting for confounding by individual variables, including age, sex, education, marital, smoking status, disease duration and co-morbidities. Because the distribution of costs were skewed, we also used a multiple linear regression to compare the mean of the cost logarithm between the HAQ-score categories.
We used a prevalence-based approach to estimate the cost of productivity losses of RA for Alberta. The number of employees with RA was estimated by multiplying the number of employees in Alberta with the prevalence of RA among employees. The cost of productivity losses of RA for Alberta was equal to the number of employees with RA multiplied the average annual cost of productivity losses per person with RA. We included both the mean and median costs for better information.

Stata MP 11.2 (StataCorp, 4905 Lakeway Drive, College Station, Texas 77845, USA) was used for analyses.

\section{RESULTS}

In total there were 1222 patients with RA interviewed at the baseline. Of this, 358 were the "currently employees" and 204 were the "previously employees" totalling 563 patients for analyses. Of the 563, number of patients in HAQ category 4 accounted for the largest share (29\%), followed by categories 3 and 5 (22\% each), 2 (13\%), and 1 (11\%). Number of patients with missing values in HAQ-score accounted for $3 \%$ of the sample (Table $\mathbf{1}$ ).

Table 2 shows the annual mean and median costs of productivity losses per patient by HAQ categories. For all HAQ-score categories, the mean (median) of the cost per patient per year was estimated at $\$ 18,242(\$ 3,840)$. The cost was increasing along with the HAQ-score increase. The lowest cost $(\$ 6,295)$ was found in category 1 and the highest $(\$ 31,095)$ in category 5 .

The differences in the annual cost of productivity losses per person between HAQ-score categories estimated from the multiple regressions are summarized in Table $\mathbf{3}$ (full regressions are available upon request). In general, the significant differences were found between the worse categories (4 and 5) and between categories 4 or 5 and the better categories $(1,2$ or 3$)$.

\section{Cost of Productivity Losses of RA for the Province of Alberta}

With the number of employees of 2,016,600 [9] and the prevalence rate of $0.74 \%$ [7], the number of employees with RA in Alberta was estimated at 14,923 . By multiplying this number with $\$ 18,242$ (the mean cost of productivity losses per patient per year in Table 2), the mean cost of productivity losses of RA for the province of Alberta was estimated at $\$ 272,225,432$. Conservatively, if median $(\$ 3,840$ - the median cost of productivity losses per patient per year in Table 2) was used for mean, the costs for province would be $\$ 57,303,706$.

\section{DISCUSSION}

There are 3 main findings of this study. First, the mean (median) of the cost of productivity losses per patient per year in Alberta, Canada is approximately $\$ 18,000(\$ 4,000)$. This estimate is clearly in the range of indirect costs reported by a review of 24 studies of costs related to RA from 8 different countries (including Canada), which is from $\$ 2,300$ to 70,300 [4]. The mean is much higher than the median indicating a skewed distribution of the costs. This is supported by other studies in showing the substantially higher cost incurred by a subset of patients [10]. 
Table 1. Descriptive Statistics

\begin{tabular}{|c|c|c|}
\hline Total Number of patients & \multicolumn{2}{|l|}{563} \\
\hline \multicolumn{3}{|l|}{ RA characteristics } \\
\hline & HAQ-score $0.0-0.5$ & $11 \%$ \\
\hline & HAQ-score $0.6-1.0$ & $13 \%$ \\
\hline & HAQ-score 1.1-1.5 & $22 \%$ \\
\hline & HAQ-score 1.6-2.0 & $29 \%$ \\
\hline & HAQ-score 2.1-3.0 & $22 \%$ \\
\hline & Unknown HAQ-score & $3 \%$ \\
\hline & Disease duration (mean) & 13 years \\
\hline \multicolumn{3}{|c|}{ Socio-Demographic Characteristics } \\
\hline & Age (mean) & 52 years \\
\hline & Male & $31 \%$ \\
\hline & Married & $66 \%$ \\
\hline & Less than high school & $9 \%$ \\
\hline & High school & $12 \%$ \\
\hline & College/university & $39 \%$ \\
\hline & Unknown education & $41 \%$ \\
\hline & Currently smoker & $1 \%$ \\
\hline & ex-smoker & $26 \%$ \\
\hline & Never smoked & $39 \%$ \\
\hline & Unknown smoking status & $34 \%$ \\
\hline \multicolumn{3}{|l|}{ Co-Morbidities } \\
\hline & Diabetes & $6 \%$ \\
\hline & Ulcerative colitis & $8 \%$ \\
\hline & Depression & $17 \%$ \\
\hline & Osteoarthritis & $39 \%$ \\
\hline & Back pain & $37 \%$ \\
\hline & Heart disease & $6 \%$ \\
\hline & High blood pressure & $23 \%$ \\
\hline & Lung disease & $6 \%$ \\
\hline & Kidney disease & $2 \%$ \\
\hline & Liver disease & $2 \%$ \\
\hline & Anemia & $8 \%$ \\
\hline & Cancer & $3 \%$ \\
\hline
\end{tabular}

Second, the cost of productivity losses per patient per year in Alberta, Canada is $\$ 6,000 ; \$ 12,000 ; \$ 14,000$; $\$ 19,000$; and $\$ 31,000$ for HAQ categories $1,2,3,4$, and 5, respectively. This information is useful for economic evaluations of new drugs or technologies improving RA patients' function (measured by HAQ-scores) using a societal perspective where productivity losses are included. Although the cost is increasing along with the HAQ-score increase, the correlation is not linear but rather has bigger changes in the worse categories as indicated by the multivariate analytical results where the significant differences in the cost are found between categories 4 and 5 , and between categories 4 or 5 and 1, 2 or 3 . This suggests that preventing HAQ-score from the worse categories may be associated with substantial savings in terms of productivity losses. For example, if there's a therapy that could change HAQ from 5 to 4 , the saving would be $\$ 8,966$ (mean) or $\$ 26,300$ (median) (Table 3). This may be supported by a study in the US where the greatest impact of HAQ-score on the cost is found between the second and third quartiles [3].

Finally, the annually average cost of productivity losses of RA for the province of Alberta is $\$ 270$ million. This accounts for about $0.1 \%$ of the province's GDP [11]. This is 3-4 times higher than the annual cost of productivity losses related to asthma ( $\$ 70-\$ 84$ million) in the province, even though the prevalence of asthma (8.5\%) is 11 times higher than that of RA [12]. Function disability caused by RA can be an explanation for this difference.

This study included people with RA who are currently employed in paid work or who stop working permanently or who retire earlier because of RA, so the results are not overestimated for lost days of unpaid work for students, homemakers, and retirees. However, the results are likely underestimated because presenteeism, care-givers' time, and premature death are not included. In addition, the results are based on self-reported estimates, so there is possibly some effect of recall bias. Also, one may argue that there is a possible selection bias as the study used a sample of some 500 individuals to represent for some 15,000 employees with RA in Alberta. However, this bias is likely small since the sample included patients in all severity levels as measured by HAQ-scores.

In conclusion, the results suggest that an improvement in the controlling of RA could have a significant economic impact in Alberta and that preventing HAQ-score from the worse categories may be associated with substantial savings in terms of productivity losses.

Table 2. Annual Costs (2010 CA\$) of Productivity Losses Per Patient by HAQ Categories

\begin{tabular}{|c|c|c|c|c|c|}
\hline HAQ Categories & $\mathbf{N}$ & Mean Cost & Median Cost & SD of Mean Cost & Mean Cost Logarithm \\
\hline \hline 1$)$ & 62 & 6,295 & 0 & 17,164 & 19,969 \\
\hline 2$)$ & 72 & 11,893 & 384 & 19,856 & 8.4 \\
\hline 3$)$ & 123 & 13,653 & 1,536 & 24,015 & 9.1 \\
\hline 4$)$ & 164 & 19,434 & 5,376 & 22,037 & 9.5 \\
\hline 5$)$ & 126 & 31,095 & 42,336 & 25,076 & 9.1 \\
\hline Unknown & 16 & 14,962 & 4,224 & 22,875 & 9.2 \\
\hline
\end{tabular}


Table 3. Differences in the Annual Costs (2010 CA\$) of Productivity Losses Per Patient Between HAQ Categories

\begin{tabular}{|c|c|c|c|}
\hline HAQ Categories & Mean Cost $(95 \%$ CI $)$ & Mean Cost Logarithm $(95 \%$ CI $)$ & Median Cost $(95 \%$ CI $)$ \\
\hline \multirow{2}{*}{ 1) vs 5) } & $-20,452$ & -1.55 & $-24,480$ \\
\hline & $(-27,419 ;-13,485)^{*}$ & $(-2.14 ;-0.97)^{*}$ & $(-28,750 ;-20,209)^{*}$ \\
\hline \multirow{2}{*}{ 1) vs 4) } & $-11,694$ & -0.97 & $-3,899$ \\
\hline & $(-18,587 ;-4,802)^{*}$ & $(-1.66 ;-0.27)^{*}$ & $(-8,656 ; 859)$ \\
\hline \multirow{2}{*}{ 1) vs 3) } & $-6,291$ & -0.12 & $-1,228$ \\
\hline & $(-11,989 ;-592)^{*}$ & $(-0.81 ; 0.58)$ & $(-2,298 ;-157)^{*}$ \\
\hline \multirow{2}{*}{ 1) vs 2) } & $-6,127$ & -0.33 & -287 \\
\hline & $(-12,794 ; 540)$ & $(-1.30 ; 0.64)$ & $(-847 ; 274)$ \\
\hline \multirow{2}{*}{ 2) vs 5) } & $-13,393$ & -0.99 & $-22,279$ \\
\hline & $(-20,346 ;-6,439)^{*}$ & $(-1.54 ;-0.44)^{*}$ & $(-31,474 ;-13,085)^{*}$ \\
\hline \multirow{2}{*}{ 2) vs 4) } & $-6,508$ & -0.50 & $-4,648$ \\
\hline & $(-13,153 ; 137)$ & $(-1.10 ; 0.10)$ & $(-6,745 ;-2550)^{*}$ \\
\hline \multirow{2}{*}{ 2) vs 3) } & -99 & 0.02 & -354 \\
\hline & $(-5,822 ; 5,624)$ & $(-0.65 ; 0.69)$ & $(-2,621 ; 1,913)$ \\
\hline \multirow{2}{*}{ 3) vs 5) } & $-12,149$ & -0.77 & $-20,253$ \\
\hline & $(-17,690 ;-6,607)^{*}$ & $(-1.18 ;-0.36)^{*}$ & $(-33,529 ;-6,978)^{*}$ \\
\hline \multirow{2}{*}{ 3) vs 4) } & $-5,815$ & -0.51 & $-2,623$ \\
\hline & $(-11,059 ;-571)^{*}$ & $(-0.95 ;-0.07)^{*}$ & $(-5,852 ; 606)$ \\
\hline \multirow{2}{*}{ 4) vs 5) } & $-8,966$ & -0.52 & $-26,300$ \\
\hline & $(-14,799 ;-3,133)^{*}$ & $(-0.89 ;-0.15)^{*}$ & $(-33,744 ;-18,857)^{*}$ \\
\hline
\end{tabular}

1) HAQ-score from 0.0 to $0.5,2) \mathrm{HAQ}$-score from 0.6 to 1.0, 3) HAQ-score from 1.1 to 1.5, 4) HAQ-score from 1.6 to 2.0, and 5) HAQ-score from 2.1 to 3.0 *Indicates significance.

\section{CONFLICT OF INTEREST}

The authors confirm that this article content has no conflict of interest.

\section{ACKNOWLEDGEMENTS}

This study was funded by Alberta Health

\section{REFERENCES}

[1] Sokka T, Krishnan E, Hakkinen A, Hannonen P. Functional disability in rheumatoid arthritis patients compared with a community population in Finland. Arthritis Rheum 2003; 48: 5963.

[2] Lajas C, Abasolo L, Bellaidel B et al. Costs and predictors of costs in rheumatoid arthritis: a prevalence-based study. Arthritis Rheum 2003; 49(1): 64-70.

[3] Yelin E, Wanke LA. An assessment of the annual and long-term direct costs of rheumatoid arthritis: the impact of poor function and functional decline. Arthritis Rheum 1999; 42: 1209-18.

[4] Rat AC, Boissier MC. Rheumatoid arthritis: direct and indirect costs. Joint Bone Spine 2002; 71(6): 518-24.
[5] McIntosh E. The costs of rheumatoid arthritis. Br J Rheumatol 1996; 35: 781-90.

[6] Yelin EK. The cost of rheumatoid arthritis: absolute, incremental and marginal estimates. J Rheumatol 1996; 23: 47-51

[7] Arthritis Alliance of Canada. The impact of arthritis in Canada: today and over the next 30 years. 2011 [cited November 22, 2011]. Available from: www.arthritisalliance.ca.

[8] Barnabe C, Thanh NX, Ohinmaa A, et al. Healthcare service utilization costs are reduced when rheumatoid arthritis patients achieve sustained remission. Ann Rheum Dis. 2012 [Epub ahead of print].

[9] Government of Alberta. Industry profiles: Public Administration Industry. 2011 [cited November 22, 2011]. Available from: http://employment.alberta.ca/documents/industry-profile-publicadministration.pdf.

[10] Kavanaugh A. Health economics: implications for novel antirheumatic therapies. Ann Rheum Dis 2005; 64: iv65-9.

[11] Statistics Canada. Real gross domestic product, expenditure-based, by province and territory. [cited June 7, 2013]. Available from: http://www.statcan.gc.ca/tables-tableaux/sumsom/101/cst01/econ50-eng.htm.

[12] Thanh NX, Ohinmaa A, Yan C. Asthma-related productivity losses in Alberta. Can J Asthma Allergy 2009; 2: 43-8.

(C) Thanh et al.; Licensee Bentham Open.

This is an open access article licensed under the terms of the Creative Commons Attribution Non-Commercial License (http://creativecommons.org/licenses/by$\mathrm{nc} / 3.0 /$ ) which permits unrestricted, non-commercial use, distribution and reproduction in any medium, provided the work is properly cited. 